B.I. Kuznetsov, T.B. Nikitina, I.V. Bovdui, V.V. Kolomiets, B.B. Kobylianskiy

\title{
REDUCTION OF MAGNETIC FIELD LEVEL IN RESIDENTIAL OLD BUILDINGS FROM OVERHEAD POWER LINES BY MEANS OF ACTIVE SCREENING
}

\begin{abstract}
Aim. Reduction of the magnetic field induction to the level of modern sanitary standards by means of active screening in residential old buildings which are located near existing typical overhead power lines are considered. Active shielding of the magnetic field inside a single-storey and multi-storey building is considered. During the design the number, configurations, spatial arrangement of the shielding windings, as well as the currents in the shielding windings were determined. Methodology. The design problem for the system of active shielding reduced to solving the minimax vector optimization problem. The vector of objective function in this minimax problem is calculated based on Biot-Savart's law. The solution of this problem is based on multi-agent optimization algorithms. Results. The results of theoretical and experimental studies of the systems of active shielding of the magnetic field generated by various overhead power lines inside a single and multi-storey building are presented. Originality. The possibility of reducing the induction of the initial magnetic field inside the shielded space to the level of sanitary standards is shown. Practical value. From the point of view of the practical implementation for a reasonable choice of the number and spatial arrangement of shielding windings of systems for active shielding of the magnetic field generated by various overhead power lines inside residential buildings of different storey's are given. References 47 , figures 7.
\end{abstract}

Key words: overhead power line, magnetic field, system of active screening, computer simulation, experimental research.

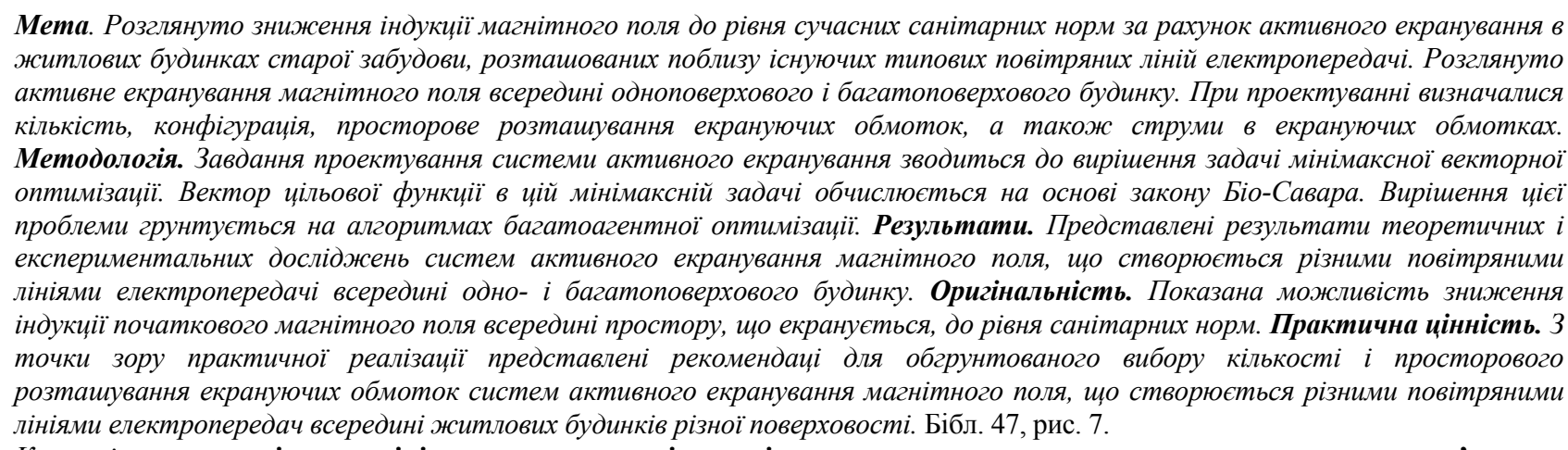
Ключові слова: повітряна лінія електропередачі, магнітне поле, система активного екранування, комп'ютерне моделювання, експериментальні дослідження.

Introduction. Existing high-voltage overhead power lines, located in residential areas of most developed countries, are the main sources of magnetic field of industrial frequency, which has a massive effect on the population and is more dangerous to health than the electric field [1-4]. Experts of the World Health Organization in the late 20th century discovered the carcinogenic properties of the magnetic field of overhead power lines with its weak but long-lasting effects on humans. Therefore, in the last 20 years the world has been actively implementing and constantly strengthening sanitary norms from the maximum allowable level of induction of magnetic field $50-60 \mathrm{~Hz}$ for the population, intensive development of methods for normalization of magnetic field [5-11].

Recently, strict sanitary standards for the induction of a magnetic field of $50 \mathrm{~Hz}(0,5 \mu \mathrm{T}$ for the population) were introduced for the first time in the regulations of Ukraine. However, in Ukraine these norms are for most of the existing 10-330 kV overhead power lines, which were built during the last 50 years without taking into account the current requirements for magnetic field, are not fulfilled.

Thus, as shown by the calculations and results of numerous experiments $[1,2]$, the maximum allowable level of induction of magnetic field at the boundary of the sanitary protection zones of existing substations, previously determined only by electric field, may be exceeded by more than an order of magnitude. This poses a threat to the health of hundreds of thousands of people living closer than $100 \mathrm{~m}$ from overhead power lines.

Moreover, often residential old buildings are generally located near power lines, as it is shown in Fig. 1.

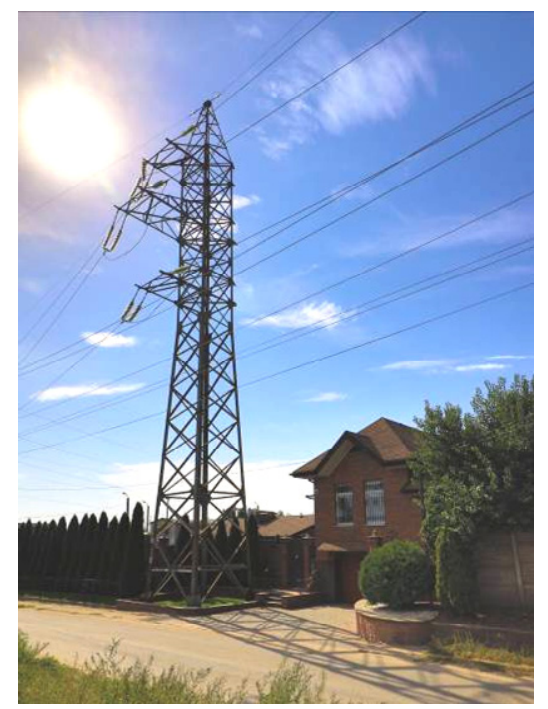

Fig. 1. Location of residential old buildings near power lines

This situation requires urgent measures to reduce to a safe level induction of high-voltage overhead power lines in nearby residential houses. Such normalization of

(C) B.I. Kuznetsov, T.B. Nikitina, I.V. Bovdui, V.V. Kolomiets, B.B. Kobylianskiy 
magnetic field can be carried out either by reconstruction of the overhead power lines, or by shielding residential buildings from the magnetic field of overhead power lines.

Reconstruction is the most effective method to reduce to a safe level induction of magnetic field.

Higher shielding efficiency of magnetic field submarines (up to 10) with less metal capacity is possible to provide methods of active shielding of magnetic field [12-18]. Their essence is automatic formation in a closed structure by means of special windings of the compensating magnetic field with such spatial time structure, the superposition of which with magnetic field submarine in the protection zone is minimized to a safe level. Active shielding technology does not allow relatively inexpensive means to solve socially important problems.

The technology of active shielding of magnetic field of operating substations has been used by the majority for more than 10 years developed countries, such as the United States, Italy, Spain and Israel [5-11]. In works [12-18], methods for designing of such systems of active screening based on genetic optimization algorithms were developed. However, these works do not consider the issues of the synthesis of robust systems of active screening, the characteristics of which are not sensitive to changes in the parameters and, possibly, the structure of the control object and the parameters of the original magnetic field [19-22].

In Ukraine in residential buildings of core city buildings single-storey and multi-storey buildings most often are located near existing $10-330 \mathrm{kV}$ overhead power lines including single-circuit overhead power lines with a triangular suspension of wires, double-circuit overhead power lines with a suspension of «barrel»-type wires.

The purpose of the work is to reduce the magnetic field induction in residential buildings of old buildings which are located near existing various types overhead power lines to the level of modern sanitary standards by means of active screening.

Statement of the research problem. The mathematical model of the vector induction $\boldsymbol{B}_{o}\left(P_{i}, \boldsymbol{I}_{0}(t), t\right)$ of the initial magnetic field [22-28] in the form of the sum of the vector inductions $\boldsymbol{B}_{o l}\left(P_{i}, \boldsymbol{I}_{l}(t)\right)$ generated by all $L$ currents $I_{l}(t)$ in the conductors $l$ of the power transmission line at a point $P_{i}$ at a time $t$ is based on the Biot-Savart law in the following form

$$
\boldsymbol{B}_{o}\left(P_{i}, \boldsymbol{I}_{0}(t), t\right)=\sum_{l=1}^{L} \boldsymbol{B}_{o l}\left(P_{i}, I_{l}(t)\right),
$$

here a vector of power transmission line currents $\boldsymbol{I}_{0}(t)$ is introduced, the components of which are the currents $I_{l}(t)$ in $l$ current conductors of the power transmission line $\boldsymbol{I}_{0}(t)=\left\{I_{l}(t)\right\}$.

The shielding magnetic field induction $\boldsymbol{B}_{y}\left(P_{i}, \boldsymbol{I}_{y}(t), t\right)$ generated by $M$ control windings can be calculated similarly as the sum of the inductions $\boldsymbol{B}_{y m}\left(P_{i}, I_{y m}(t), t\right)$ generated by the $m$ currents $I_{l}(t)$ of the shielding windings at a point $P_{i}$ at a time $t$ in the following form

$$
\boldsymbol{B}_{y}\left(P_{i}, \boldsymbol{I}_{y}(t), t\right)=\sum_{m=1}^{M} \boldsymbol{B}_{y m}\left(P_{i}, I_{y m}(t), t\right),
$$

here the vector $\boldsymbol{I}_{y}(t)$ of currents of the shielding windings is introduced, the components of which are $I_{l}(t)$ the currents in $m$ shielding windings $\boldsymbol{I}_{y}(t)=\left\{I_{y m}(t)\right\}$.

With the help of the $M$ windings of the system of active screening, it is necessary to generate a magnetic field with the induction $\boldsymbol{B}_{y}\left(P_{i}, \boldsymbol{I}_{y}(t), t\right)$ at the point $P_{i}$ of the considered space, with the help of which the induction $\boldsymbol{B}_{o}\left(P_{i}, \boldsymbol{I}_{0}(t), t\right)$ of initial magnetic field in the point $P_{i}$ of considered space is compensated, so that the induction $\boldsymbol{B}\left(P_{i}, \boldsymbol{I}_{0}(t), \boldsymbol{I}_{y}(t), t\right)$ of the total magnetic field generated by currents $\boldsymbol{I}_{0}(t)$ of wires of power lines and currents $\boldsymbol{I}_{y}(t)$ of control windings at all points $P_{i}$, of the considered space

$$
\begin{aligned}
& \boldsymbol{B}\left(P_{i}, \boldsymbol{I}_{o}(t), \boldsymbol{I}_{y}(t), t\right)= \\
& =\boldsymbol{B}_{o}\left(P_{i}, \boldsymbol{I}_{0}(t), t\right)+\ldots+\boldsymbol{B}_{y}\left(P_{i}, \boldsymbol{I}_{y}(t), t\right),
\end{aligned}
$$

does not exceed the level of sanitary standards for all points $P_{i}$ of the considered screening space.

The task of designing of the system of active shielding is to determine the number and spatial location of the compensating windings, as well as the currents in these windings.

Solution method. In the process of designing of the system of active shielding, it is necessary to determine the amount $M$ of compensating windings and the coordinates $\boldsymbol{X}$ and $\boldsymbol{Y}$ of the spatial arrangement of the compensating windings, as well as the currents $\boldsymbol{I}_{y}(t)$ in these windings [20]-[23]. Let us introduce a vector of the sought-for design parameters of the system of active shielding, the components of which are the amount $M$ of compensating windings and the coordinates of the $\boldsymbol{X}$ and $\boldsymbol{Y}$ of the spatial arrangement of the compensating windings, as well as the currents of the $\boldsymbol{I}_{y}(t)$ in these windings. Then, for a given value of the $M$ quantity and the coordinates of the $\boldsymbol{X}$ and $\boldsymbol{Y}$ of the spatial arrangement of the compensating windings, as well as the $\boldsymbol{I}_{y}(t)$ currents in these windings, the mathematical model of the induction $\boldsymbol{B}_{y}\left(P_{i}, \boldsymbol{I}_{y}(t), t\right)$ of the magnetic field generated at the point $P_{i}$ of the space under consideration by all compensating windings is also based on the Biot-Savart law.

When the system of active shielding operates at the points of the shielding space located closer to the power transmission line, undercompensation of the initial magnetic field is possible, since the induction of the magnetic field generated by the compensation windings decreases faster than the induction of the initial magnetic field generated by the power transmission line. On the other hand, at the points of the shielding space located further from the power transmission line, overcompensation of the initial magnetic field is possible, since the induction of the magnetic field generated by the compensation windings near these windings has a significantly greater value of the induction of the initial magnetic field generated by the power transmission line in these same points [24-28]. Therefore, to reduce the number of points taken into account, you can take a limited number of points in the shielding space near the transmission line and the most distant from the transmission line.

A feature of the design problem is that the parameters of the initial magnetic field, its induction and the spatio-temporal characteristic, due, in particular, to the 
currents in the wires of the power transmission line, are not known exactly in advance and changes in time-during the day, the time of the year and others. In addition, the parameters of the active screening system, in particular, the geometric dimensions of the compensating windings and regulators, firstly, are implemented with some error and, secondly, change during the operation of the system of active shielding.

Therefore, the design of system of active shielding must be carried out taking into account the uncertainty of both the parameters of the initial magnetic field and the system of active shielding parameters [29-35]. Let us introduce a vector of uncertainties, the components of which are the deviations of the parameters of the initial magnetic field and the parameters of the system of active shielding from their nominal values adopted in the design of the system of active shielding.

Let's reduce the design of the system of active shielding to solving the optimization problem. In the presence of uncertainties in the system, the design of a robust system is usually reduced to the «worst» case, when the uncertainty vector behaves the most maliciously and maximally degrades the compensation of the initial magnetic field with the help of compensating windings [36-38]. Then the design problem for the system of active shielding can be reduced to solving the following maximin vector optimization problem [39-41]. The vector objective function in this minimax problem is calculated based on Biot-Savart's law.

The solution to this problem is based on multi-agent optimization algorithms [42-47].

Results of modeling and experimental research. In residential buildings of core city buildings which are located near existing typical power lines the most widespread are single-circuit $110 \mathrm{kV}$ transmission lines with a triangular suspension of wires. Moreover, in the area of laying these power lines, single-story residential buildings are most often in the immediate vicinity. The layout of power transmission line, single-story residential building, in which it is necessary to reduce the induction of the initial magnetic field to the level of modern sanitary standards, and compensating windings are shown in Fig. 2. As a result of the design of the system of active shielding two compensating windings was calculated.

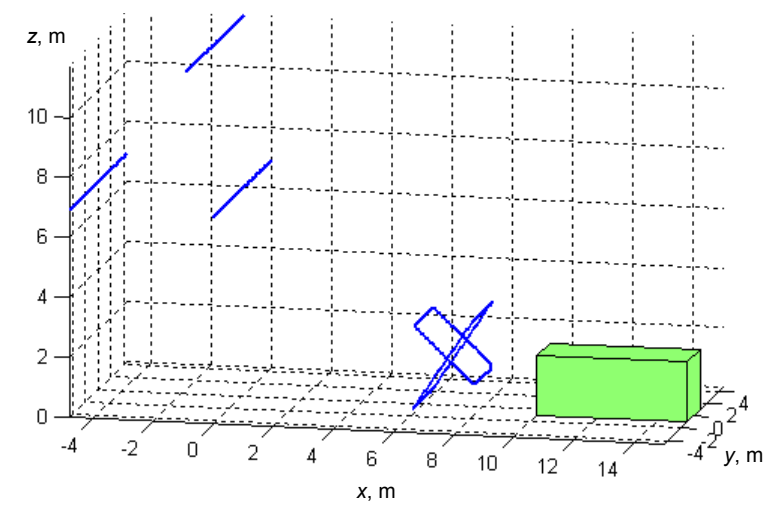

Fig. 2. The layout of single-circuit $110 \mathrm{kV}$ transmission lines, compensating windings and one-story residential building

In Fig. 3 is shown two compensating windings of experimental plant of system of active shielding.

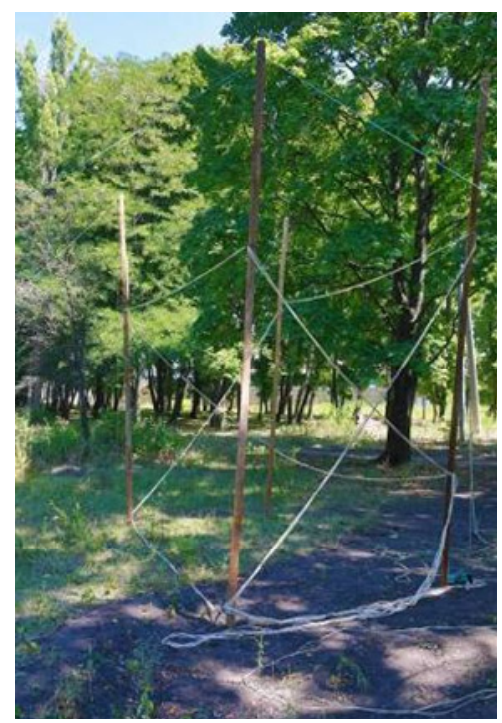

Fig. 3. Location of three compensating windings of experimental plant of system of active shielding

In Fig. 4 are shown modeling and experimental dependences of the induction of the initial and resulting magnetic field as a function of the distance from the power transmission line in the house, where it is necessary to reduce the level of induction of the initial magnetic field generated by the power transmission line. As can be seen from this figure, the level of induction of the initial magnetic field varies from $0,65 \mu \mathrm{T}$ to $1,5 \mu \mathrm{T}$. The induction of the total magnetic field in the shielding zone practically does not exceed the level of sanitary standards.

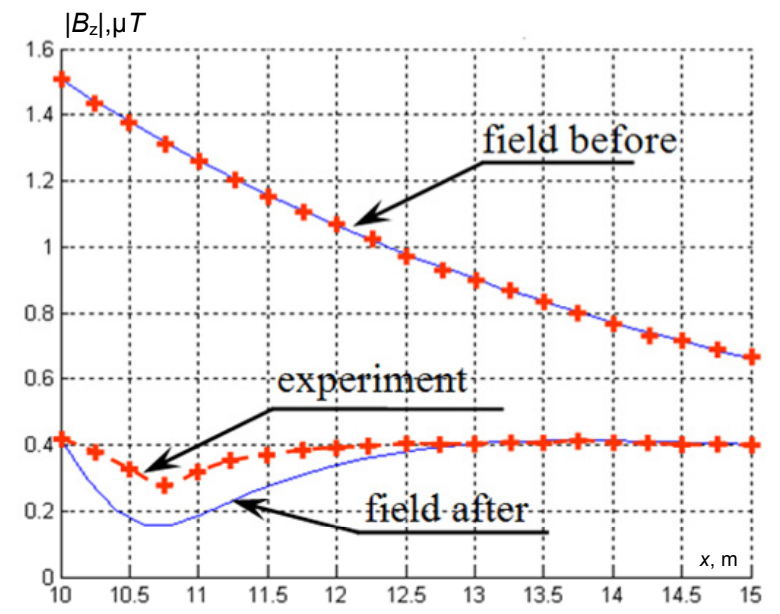

Fig. 4. Comparison of magnetic flux density between measurements and simulations with and without system of active shielding

Single-circuit $110 \mathrm{kV}$ power transmission lines with a triangular suspension of wires often run near multistorey buildings of core city buildings. The layout of such a power transmission line, compensating windings and a multi-storey residential building, in which it is necessary to reduce the induction of the initial magnetic field to the level of modern sanitary standards, are shown in Fig. 5. As a result of design of the system of active shielding, the coordinates of three compensating windings were calculated.

In Fig. 6 are shown three compensating windings of experimental plant of system of active shielding. 


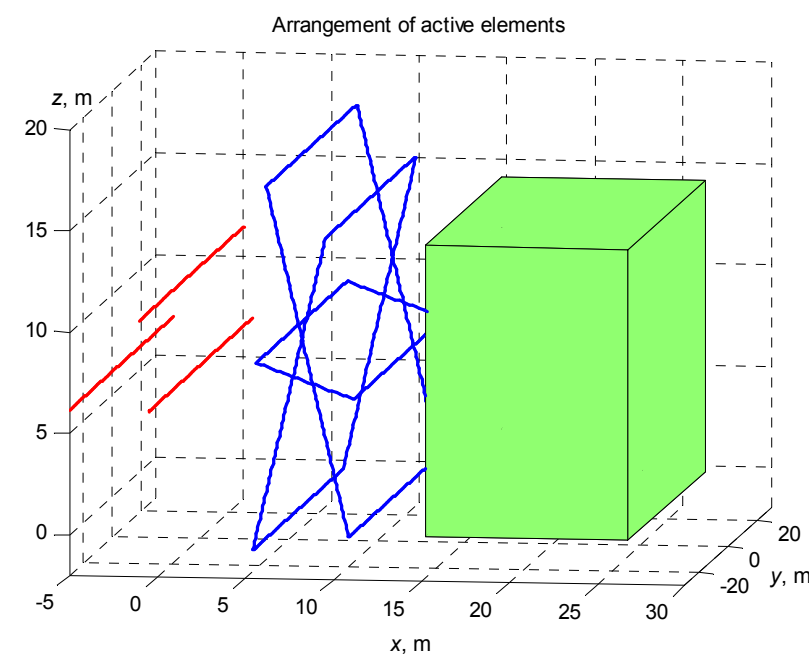

Fig. 5. The layout of single-circuit $110 \mathrm{kV}$ transmission lines with a triangular suspension of wires and multi-storey residential building

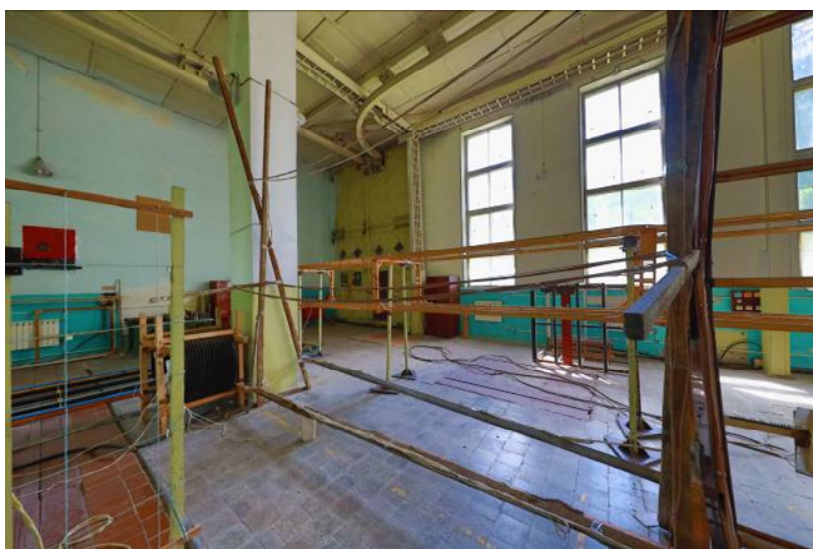

Fig. 6. Location of three compensating windings of experimental plant of system of active shielding

Results of modeling and experimental dependences of the initial and resulting magnetic field induction as a function of the distance from the power transmission line are shown in Fig. 7 The level of the initial magnetic field induction varies from $2,25 \mu \mathrm{T}$ to $0,8 \mu \mathrm{T}$.

The level of the total magnetic field induction in the house, where it is necessary to reduce the level of the initial magnetic field induction does not exceed the sanitary standards level.

Double-circuit overhead power lines with a suspension of «barrel»-type wires also often run near single-storey and multi-storey buildings of city core buildings.

Such overhead power lines generate a weakly polarized magnetic field, the space-time characteristic of which is a highly elongated ellipse. To effectively compensate for such a magnetic field, one screening winding is sufficient. Such a winding generates magnetic field, the space-time characteristic of which is a straight line. Therefore, with the help of such a shielding winding, it is possible to compensate for the major axis of the space-time characteristic ellipse of the initial magnetic field and to realize a sufficiently high shielding efficiency.

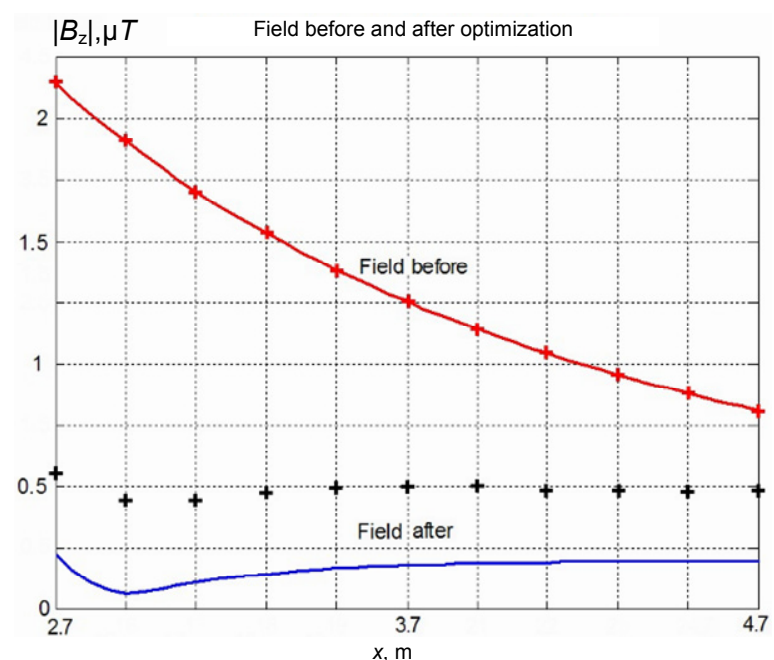

Fig. 7. Comparison of magnetic flux density between measurements (solid lines) and simulations $(+)$ with and without system of active shielding

As a result of design of the system of active shielding for such overhead power lines the coordinate's only single compensating winding were calculated. During modeling and experimental research of such system of active shielding with only single compensating winding was shown the possibility to reduce the induction of the initial magnetic field to the level of modern sanitary standards in residential buildings of city core buildings including single-storey and multi-storey buildings which are located near existing double-circuit overhead power lines with a suspension of «barrel»-type wires.

\section{Conclusions.}

1. The method for the design problem for the system of active screening has been developed. During the design the number, configuration, spatial arrangement of the shielding windings and the currents in the shielding windings were determined. The design problem is reduced to solving the maximin vector optimization problem. The vector objective function in this minimax problem is calculated based on Biot-Savart's law. The solution of this problem is based on multi-agent optimization algorithms.

2. On the basis of the developed method the design of the different type of systems of active screening to reduce the magnetic field induction to the level of modern sanitary standards for residential buildings of core city buildings have been carried out. These systems contain different number screening coils and include single-storey and multi-storey buildings which are located near existing typical power lines including single-circuit overhead power lines with a triangular suspension of wires, doublecircuit overhead power lines with a suspension of «barrel»-type wires.

3. As a result of computer simulation and experimental studies of the synthesized systems of active screening, it is shown that with the help of the synthesized systems, the level of induction of the magnetic field in single-storey and multi-storey buildings generated by different types of high-voltage power lines are reduced to the sanitary standards of Ukraine.

Conflict of interest. The authors declare that they have no conflicts of interest. 


\section{REFERENCES}

1. Rozov V.Yu., Grinchenko V.S., Yerisov A.V., Dobrodeyev P.N. Efficient shielding of three-phase cable line magnetic field by passive loop under limited thermal effect on power cables. Electrical Engineering \& Electromechanics, 2019, no. 6, pp. 5054. doi: https://doi.org/10.20998/2074-272x.2019.6.07.

2. Rozov V., Grinchenko V. Simulation and analysis of power frequency electromagnetic field in buildings closed to overhead lines. 2017 IEEE First Ukraine Conference on Electrical and Computer Engineering (UKRCON), Kyiv, UKraine, 2017, pp. 500-503. doi: https://doi.org/10.1109/ukrcon.2017.8100538.

3. Rozov V.Yu., Kundius K.D., Pelevin D.Ye. Active shielding of external magnetic field of built-in transformer substations. Electrical Engineering \& Electromechanics, 2020, no. 3, pp. 2430. doi: https://doi.org/10.20998/2074-272x.2020.3.04.

4. Rozov V.Y., Zavalnyi A.V., Zolotov S.M., Gretskikh S.V. The normalization methods of the static geomagnetic field inside houses. Electrical Engineering \& Electromechanics, 2015, no. 2, pp. 35-40. doi: https://doi.org/10.20998/2074272x.2015.2.07.

5. Salceanu A., Paulet M., Alistar B.D., Asiminicesei O. Upon the contribution of image currents on the magnetic fields generated by overhead power lines. 2019 International Conference on Electromechanical and Energy Systems (SIELMEN). 2019. doi: https://doi.org/10.1109/sielmen.2019.8905880.

6. Del Pino Lopez J.C., Romero P.C. Influence of different types of magnetic shields on the thermal behavior and ampacity of underground power cables. IEEE Transactions on Power Delivery, Oct. 2011, vol. 26, no. 4, pp. 2659-2667. doi: https://doi.org/10.1109/tpwrd.2011.2158593.

7. Ippolito L., Siano P. Using multi-objective optimal power flow for reducing magnetic fields from power lines. Electric Power Systems Research, Feb. 2004, vol. 68, no. 2, pp. 93-101. doi: https://doi.org/10.1016/s0378-7796(03)00151-2.

8. Barsali S., Giglioli R., Poli D. Active shielding of overhead line magnetic field: Design and applications. Electric Power Systems Research, May 2014, vol. 110, pp. 55-63. doi: https://doi.org/10.1016/i.epsr.2014.01.005.

9. Bavastro D., Canova A., Freschi F., Giaccone L., Manca M. Magnetic field mitigation at power frequency: design principles and case studies. IEEE Transactions on Industry Applications, May 2015, vol. 51, no. 3, pp. 2009-2016. doi: https://doi.org/10.1109/tia.2014.2369813.

10. Beltran H., Fuster V., García M. Magnetic field reduction screening system for a magnetic field source used in industrial applications. 9 Congreso Hispano Luso de Ingeniería Eléctrica (9 CHLIE), Marbella (Málaga, Spain), 2005, pp. 84-99. Available

at:

https://www.researchgate.net/publication/229020921 Magnetic

field reduction screening system for a magnetic field sour ce used in industrial applications (Accessed 22.06.2021).

11. Bravo-Rodríguez J., Del-Pino-López J., Cruz-Romero P. A Survey on Optimization Techniques Applied to Magnetic Field Mitigation in Power Systems. Energies, 2019, vol. 12, no. 7, p. 1332. doi: https://doi.org/10.3390/en12071332.

12. Canova A., del-Pino-López J.C., Giaccone L., Manca M. Active Shielding System for ELF Magnetic Fields. IEEE Transactions on Magnetics, March 2015, vol. 51, no. 3, pp. 1-4. doi: https://doi.org/10.1109/tmag.2014.2354515.

13. Canova A., Giaccone L. Real-time optimization of active loops for the magnetic field minimization. International Journal of Applied Electromagnetics and Mechanics, Feb. 2018, vol. 56, pp. 97-106. doi: https://doi.org/10.3233/jae-172286.

14. Canova A., Giaccone L., Cirimele V. Active and passive shield for aerial power lines. Proc. of the 25th International Conference on Electricity Distribution (CIRED 2019), 3-6 June 2019, Madrid, Spain. Paper no. 1096. Available at: https://www.cired-repository.org/handle/20.500.12455/290 (Accessed 28.10.2020).
15. Canova A., Giaccone L. High-performance magnetic shielding solution for extremely low frequency (ELF) sources. CIRED - Open Access Proceedings Journal, Oct. 2017, vol. 2017, no. 1, pp. 686-690. doi: https://doi.org/10.1049/oapcired.2017.1029.

16. Celozzi S. Active compensation and partial shields for the power-frequency magnetic field reduction. 2002 IEEE International Symposium on Electromagnetic Compatibility, Minneapolis, MN, USA, 2002, vol. 1, pp. 222-226. doi: https://doi.org/10.1109/isemc.2002.1032478.

17. Celozzi S., Garzia F. Active shielding for power-frequency magnetic field reduction using genetic algorithms optimization. IEE Proceedings - Science, Measurement and Technology, 2004, vol. 151, no. 1, pp. 2-7. doi: https://doi.org/10.1049/ipsmt:20040002.

18. Celozzi S., Garzia F. Magnetic field reduction by means of active shielding techniques. WIT Transactions on Biomedicine and Health, 2003, vol. 7, pp. 79-89. doi: https://doi.org/10.2495/ehr030091.

19. Martynenko G. Practical application of the analytical method of electromagnetic circuit analysis for determining magnetic forces in active magnetic bearings. 2020 IEEE Problems of Automated Electrodrive. Theory and Practice (PAEP), 2020, pp. 1-4, doi: https://doi.org/10.1109/paep49887.2020.9240774.

20. Martynenko G., Martynenko V. Modeling of the dynamics of rotors of an energy gas turbine installation using an analytical method for analyzing active magnetic bearing circuits. 2020 IEEE KhPI Week on Advanced Technology (KhPIWeek), 2020, pp. 9297 .doi: https://doi.org/10.1109/KhPIWeek51551.2020.9250156.

21. Buriakovskyi S.G., Maslii A.S., Pasko O.V., Smirnov V.V. Mathematical modelling of transients in the electric drive of the switch - the main executive element of railway automation. Electrical Engineering \& Electromechanics, 2020, no. 4, pp. 1723. doi: https://doi.org/10.20998/2074-272X.2020.4.03.

22. Ostroverkhov M., Chumack V., Monakhov E., Ponomarev A. Hybrid Excited Synchronous Generator for Microhydropower Unit. 2019 IEEE 6th International Conference on Energy Smart Systems (ESS), Kyiv, Ukraine, 2019, pp. 219-222. doi: https://doi.org/10.1109/ess.2019.8764202.

23. Ostroverkhov M., Chumack V., Monakhov E. Ouput Voltage Stabilization Process Simulation in Generator with Hybrid Excitation at Variable Drive Speed. 2019 IEEE 2nd Ukraine Conference on Electrical and Computer Engineering (UKRCON), Lviv, Ukraine, 2019, pp. 310-313. doi: https://doi.org/10.1109/ukrcon.2019.8879781.

24. Tytiuk V., Chornyi O., Baranovskaya M., Serhiienko S., Zachepa I., Tsvirkun L., Kuznetsov V., Tryputen N. Synthesis of a fractional-order $\mathrm{PI}^{\lambda} \mathrm{D}^{\mu}$-controller for a closed system of switched reluctance motor control. Eastern-European Journal of Enterprise Technologies, 2019, no. 2 (98), pp. 35-42. doi: https://doi.org/10.15587/1729-4061.2019.160946.

25. Zagirnyak M., Chornyi O., Zachepa I. The autonomous sources of energy supply for the liquidation of technogenic accidents. Przeglad Elektrotechniczny, 2019, no. 5, pp. 47-50. doi: https://doi.org/10.15199/48.2019.05.12.

26. Chornyi O., Serhiienko S. A virtual complex with the parametric adjustment to electromechanical system parameters. Technical Electrodynamics, 2019, pp. 38-41. doi: https://doi.org/10.15407/techned2019.01.038.

27. Shchur I., Kasha L., Bukavyn M. Efficiency Evaluation of Single and Modular Cascade Machines Operation in Electric Vehicle. 2020 IEEE 15th International Conference on Advanced Trends in Radioelectronics, Telecommunications and Computer Engineering (TCSET), Lviv-Slavske, Ukraine, 2020, pp. 156161. doi: https://doi.org/10.1109/tcset49122.2020.235413.

28. Shchur I., Turkovskyi V. Comparative Study of Brushless DC Motor Drives with Different Configurations of Modular Multilevel Cascaded Converters. 2020 IEEE 15th International Conference on Advanced Trends in Radioelectronics, 
Telecommunications and Computer Engineering (TCSET), Lviv-Slavske, Ukraine, 2020, pp. 447-451. doi: https://doi.org/10.1109/tcset49122.2020.235473.

29. Ostroumov I., Kuzmenko N., Sushchenko O., Pavlikov V., Zhyla S., Solomentsev O., Zaliskyi M., Averyanova Y., Tserne E., Popov A., Volosyuk V., Ruzhentsev N., Dergachov K., Havrylenko O., Kuznetsov B., Nikitina T., Shmatko O. Modelling and simulation of DME navigation global service volume. Advances in Space Research, 2021, vol. 68, no. 8, pp. 3495-3507. doi: https://doi.org/10.1016/j.asr.2021.06.027.

30. Averyanova Y., Sushchenko O., Ostroumov I., Kuzmenko N., Zaliskyi M., Solomentsev O., Kuznetsov B., Nikitina T., Havrylenko O., Popov A., Volosyuk V., Shmatko O., Ruzhentsev N., Zhyla S., Pavlikov V., Dergachov K., Tserne E. UAS cyber security hazards analysis and approach to qualitative assessment. In: Shukla S., Unal A., Varghese Kureethara J., Mishra D.K., Han D.S. (eds) Data Science and Security. Lecture Notes in Networks and Systems, 2021, vol. 290, pp. 258-265. Springer, Singapore. doi: https://doi.org/10.1007/978-981-164486-3 28.

31. Zaliskyi M., Solomentsev O., Shcherbyna O., Ostroumov I., Sushchenko O., Averyanova Y., Kuzmenko N., Shmatko O., Ruzhentsev N., Popov A., Zhyla S., Volosyuk V., Havrylenko O., Pavlikov V., Dergachov K., Tserne E., Nikitina T., Kuznetsov B. Heteroskedasticity analysis during operational data processing of radio electronic systems. In: Shukla S., Unal A., Varghese Kureethara J., Mishra D.K., Han D.S. (eds) Data Science and Security. Lecture Notes in Networks and Systems, 2021, vol. 290, pp. 168-175. Springer, Singapore. doi: https://doi.org/10.1007/978-981-16-4486-3 18.

32. Sushchenko O.A. Robust control of angular motion of platform with payload based on $\mathrm{H}_{\infty}$-synthesis. Journal of Automation and Information Sciences, 2016, vol. 48, no. 12, pp. 13-26. doi: https://doi.org/10.1615/jautomatinfscien.v48.i12.20. 33. Chikovani V., Sushchenko O. Self-compensation for disturbances in differential vibratory gyroscope for space navigation. International Journal of Aerospace Engineering, 2019, vol. 2019, Article ID 5234061, 9 p. doi: https://doi.org/10.1155/2019/5234061.

34. Gal'chenko, V.Y., Vorob'ev, M.A. Structural synthesis of attachable eddy-current probes with a given distribution of the probing field in the test zone. Russian Journal of Nondestructive Testing, Jan. 2005, vol. 41, no. 1, pp. 29-33. doi: https://doi.org/10.1007/s11181-005-0124-7.

35. Halchenko, V.Y., Ostapushchenko, D.L. \& Vorobyov, M.A. Mathematical simulation of magnetization processes of arbitrarily shaped ferromagnetic test objects in fields of given spatial configurations. Russian Journal of Nondestructive Testing, Sep. 2008, vol. 44, no. 9, pp. 589-600. doi: https://doi.org/10.1134/S1061830908090015.

36. Ostroumov I., Kuzmenko N., Sushchenko O., Zaliskyi M., Solomentsev O., Averyanova Y., Zhyla S., Pavlikov V., Tserne E., Volosyuk V., Dergachov K., Havrylenko O., Shmatko O., Popov A., Ruzhentsev N., Kuznetsov B., Nikitina T. A probability estimation of aircraft departures and arrivals delays. In: Gervasi O. et al. (eds) Computational Science and Its Applications - ICCSA 2021. ICCSA 2021. Lecture Notes in Computer Science, vol. 12950, pp. 363-377. Springer, Cham. doi: https://doi.org/10.1007/978-3-030-86960-1 26.

37. Chystiakov P., Chornyi O., Zhautikov B., Sivyakova G. Remote control of electromechanical systems based on computer simulators. 2017 International Conference on Modern Electrical and Energy Systems (MEES), Kremenchuk, Ukraine, 2017, pp. 364-367. doi: https://doi.org/10.1109/mees.2017.8248934.

38. Zagirnyak M., Bisikalo O., Chorna O., Chornyi O. A Model of the Assessment of an Induction Motor Condition and Operation Life, Based on the Measurement of the External Magnetic Field. 2018 IEEE 3rd International Conference on Intelligent Energy and Power Systems (IEPS), Kharkiv, 2018, pp. 316-321. doi: https://doi.org/10.1109/ieps.2018.8559564.

39. Ummels M. Stochastic Multiplayer Games Theory and Algorithms. Amsterdam University Press, 2010. 174 p.

40. Shoham Y., Leyton-Brown K. Multiagent Systems: Algorithmic, Game-Theoretic, and Logical Foundations. Cambridge University Press, 2009. 504 p.

41. Ray T., Liew K.M. A Swarm Metaphor for Multiobjective Design Optimization. Engineering Optimization, 2002, vol. 34, no. 2, pp. 141-153. doi: https://doi.org/10.1080/03052150210915. 42. Zilzter Eckart. Evolutionary algorithms for multiobjective optimizations: methods and applications. PhD Thesis Swiss Federal Institute of Technology, Zurich, 1999. $114 \mathrm{p}$.

43. Xiaohui Hu, Eberhart R.C., Yuhui Shi. Particle swarm with extended memory for multiobjective optimization. Proceedings of the 2003 IEEE Swarm Intelligence Symposium. SIS'03 (Cat. No.03EX706), Indianapolis, IN, USA, 2003, pp. 193-197. doi: https://doi.org/10.1109/sis.2003.1202267.

44. Pulido G.T., Coello C.A.C. A constraint-handling mechanism for particle swarm optimization. Proceedings of the 2004 Congress on Evolutionary Computation (IEEE Cat. No.04TH8753), Portland, OR, USA, 2004, vol. 2, pp. 13961403. doi: https://doi.org/10.1109/cec.2004.1331060.

45. Michalewicz Z., Schoenauer M. Evolutionary Algorithms for Constrained Parameter Optimization Problems. Evolutionary Computation, 1996, vol. 4, no. 1, pp. 1-32. doi: https://doi.org/10.1162/evco.1996.4.1.1.

46. Parsopoulos K.E., Vrahatis M.N. Particle swarm optimization method for constrained optimization problems. Proceedings of the Euro-International Symposium on Computational Intelligence, 2002, pp. 174-181.

47. Xin-She Yang, Zhihua Cui, Renbin Xiao, Amir Hossein Gandomi, Mehmet Karamanoglu. Swarm Intelligence and BioInspired Computation: Theory and Applications, Elsevier Inc., 2013. $450 \mathrm{p}$.

Received 20.08.2021 Accepted 25.09.2021 Published 26.10.2021

B.I. Kuznetsov ${ }^{1}$, Doctor of Technical Science, Professor, T.B. Nikitina ${ }^{2}$, Doctor of Technical Science, Professor, I.V. Bovdui ${ }^{1}, P h D$, Senior Research Scientist,

V.V. Kolomiets ${ }^{3}$, PhD, Associate Professor,

B.B. Kobylianskiy ${ }^{3}, P h D$, Associate Professor,

${ }^{1}$ State Institution «Institute of Technical Problems of Magnetism of the National Academy of Sciences of Ukraine», 19, Industrialna Str., Kharkiv, 61106, Ukraine.

e-mail: kuznetsov.boris.i@gmail.com (Corresponding author)

${ }^{2}$ Kharkov National Automobile and Highway University,

25, Yaroslava Mudroho Str., Kharkov, 61002, Ukraine, e-mail: tatjana55555@gmail.com

${ }^{3}$ Educational scientific professional pedagogical Institute of Ukrainian Engineering Pedagogical Academy,

9a, Nosakov Str., Bakhmut, Donetsk Region, 84511, Ukraine, e-mail:nnppiuipa@ukr.net

\section{How to cite this article:}

Kuznetsov B.I., Nikitina T.B., Bovdui I.V., Kolomiets V.V., Kobylianskiy B.B. Reduction of magnetic field level in residential old buildings from overhead power lines by means of active screening. Electrical Engineering \& Electromechanics, 2021, no. 5, pp. 24-29. doi: https://doi.org/10.20998/2074-272X.2021.5.04. 